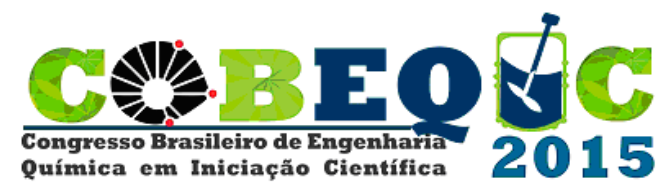

\title{
SINTESE DE REDES DE TRATAMENTO DE EFLUENTES APLICADA A UM MODELO DE GERENCIAMENTO DE REÚSO DE AGUA
}

\author{
P. C. LION ${ }^{1}$, M. S. SANTOS ${ }^{2}$, F. S. FRANCISCO ${ }^{2}$, D. J. S. A. AUDEH ${ }^{2}$, R. C. MIRRE², F. \\ L. P. PESSOA ${ }^{2}$ \\ ${ }^{1}$ Universidade Federal do Rio de Janeiro, Escola Politécnica \\ ${ }^{2}$ Universidade Federal do Rio de Janeiro, Escola de Química, Departamento de Engenharia Química \\ E-mail para contato: patyclion@poli.ufrj.bre mariissantos11@gmail.com
}

\begin{abstract}
RESUMO - A necessidade de se atuar em um cenário de baixa disponibilidade de água doce e de elevação de custos com tratamento de água e efluentes industriais incentiva a aplicação de técnicas sistemáticas para conservação e uso racional da água em processos. Um importante método é o Diagrama de Fontes de Efluentes (DFE), cuja proposta é gerar redes de tratamento final do tipo centralizada e distribuída, a fim de reduzir a vazão de efluente a ser tratado e, por conseguinte, os custos a ele relacionados. Este trabalho teve como objetivo aplicar o método DFE, e propor sua utilização no contexto de um modelo de gerenciamento do uso da água na indústria. Um estudo de caso foi realizado utilizando cenários de reúso obtidos a partir de um conjunto de dados representativos de uma refinaria de petróleo. Os resultados apontam a vantagem do tratamento distribuído em relação ao centralizado. Enquanto este último gerou cerca de $940 \mathrm{t} / \mathrm{h}$ de vazão tratada, o tratamento distribuído necessitou de somente $440 \mathrm{t} / \mathrm{h}$ do efluente, apresentando um custo em torno de metade daquele alcançado pela configuração centralizada. Neste caso, o método sugere a importância da síntese de sistemas de tratamento visando à redução do consumo de água, da geração e de impactos de efluentes sobre o corpo hídrico, destacando-se como um suporte ao processo de gerenciamento de recursos hídricos na indústria.
\end{abstract}

\section{INTRODUÇÃO}

O gerenciamento do uso da água vem recebendo grande atenção atualmente, influenciado pelo aumento da demanda, e fatores que contribuem para a escassez de oferta do recurso. A legislação estabelece taxas para captação e consumo de fontes superficiais ou subterrâneas, bem como o descarte de efluentes industriais. O gerenciamento de recursos hídricos na indústria pode ser auxiliado por meio da aplicação de técnicas sistemáticas voltadas para o aproveitamento racional da água em processos. Um destes métodos é o chamado Diagrama de Fontes de Água (DFA) (Gomes et al., 2007), procedimento algorítmico-heurístico que permite gerar redes (ou fluxogramas) de água com máximo reaproveitamento (reúso e/ou reciclo), incluindo a análise de restrições de processo e regeneração de contaminantes.

Para sistematizar o gerenciamento integrado do uso da água em processos industriais, foi criado o modelo denominado P+ÁGUA (Mirre, 2012), cuja proposta está em auxiliar a 


\section{Congresso Brasileiro de Engenharia Química em Iniciação Científica Unicamp - Campinas - SP 19 a 22 de julho de 2015}

tomada de decisão quanto à identificação de cenários promissores de reúso sustentável após a aplicação do DFA. O modelo incorpora o DFA às etapas da estratégia de gestão ambiental Produção mais Limpa $(\mathrm{P}+\mathrm{L})$, focado no uso racional da água e redução de efluentes gerados. Além disso, o modelo prevê como critério final de seleção a valoração de danos potenciais sobre a qualidade dos corpos hídricos com o descarte. Uma importante análise, não contemplada pelo $\mathrm{P}+\mathrm{A} G U A$, refere-se ao tipo de tratamento final de efluentes, o qual pode ser realizado por duas vertentes: (i) configuração centralizada, na qual os efluentes são unificados para serem tratados por uma sequência de técnicas em uma central, e a (ii) distribuída, onde as correntes são tratadas em série/paralelo, de modo individualizado ou por correntes unificadas pelas características afins; ao contrário da centralizada, a configuração distribuída tem como vantagem a possibilidade de diminuir a vazão de efluente a ser tratado, viabilizando a redução de custos operacionais e de investimento.

Com abordagem semelhante ao DFA, o método chamado Diagrama de Fontes de Rejeitos (DFR), proposto por Delgado (2008), ou Diagrama de Fontes de Efluentes (DFE), conforme Pacheco (2014), permite reduzir a vazão de efluentes a ser tratado e, por conseguinte, os custos a ele relacionados. Assim, a partir de informações como vazão do efluente, concentração final do contaminante em uma unidade de tratamento, concentração do efluente tratado, concentração limite para descarte e eficiência de remoção de contaminante no regenerador, o método gera intervalos de concentração visando obter fluxogramas para sistemas de tratamento, com a menor vazão de efluente tratado possível.

Nesta linha, vale ressaltar a contribuição de Hungaro (2005), que desenvolveu um procedimento para seleção da sequência de tratamento para um conjunto de correntes de efluentes, em função da eficiência de remoção. $O$ algoritmo gerou a menor vazão para o tratamento distribuído, relativamente à configuração centralizada. As heurísticas apresentadas por Hungaro (2005) constituíram a base para o desenvolvimento do DFE (Delgado, 2008), que, por sua vez, adaptou a síntese de sistemas de regeneração diferenciada e tratamento final distribuído de efluentes, para determinar a sequência de técnicas de tratamento. Mirre et al. (2011) utilizaram o procedimento de Hungaro (2005) para comparar as configurações centralizada e distribuída em um estudo de caso de refinaria de petróleo, posterior à aplicação do DFA. Já Pacheco (2014) empregou o DFA e o DFE a dados típicos de refinarias de petróleo, demonstrando a aplicabilidade dos métodos.

A inclusão da análise de redes de tratamento final de efluentes pode ser útil na seleção de cenários alternativos e promissores de reúso. Assim, este trabalho tem como objetivo gerar redes de tratamento de efluentes com o método DFE, e propor sua incorporação aos estágios de aplicação do modelo integrado para gerenciamento do uso da água em processos industriais, denominado P+ÁGUA.

\section{METODOLOGIA}

$\mathrm{O}$ modelo $\mathrm{P}+\mathrm{A} G U A$ adota o DFA como ferramenta para reduzir a necessidade de investimento imediato nas tecnologias de tratamento, priorizando o reúso máximo nos processos. A Figura 1 ilustra a junção tríade do $\mathrm{P}+\mathrm{A} G U A$, relacionada aos aspectos econômico, ambiental e social, e propõe a incorporação do método DFE. 
Figura 1 - Representação do modelo P+ÁGUA, incluindo a proposta de incorporação da síntese de tratamento final de efluentes (adaptado de Mirre, 2012, e Pacheco, 2014).

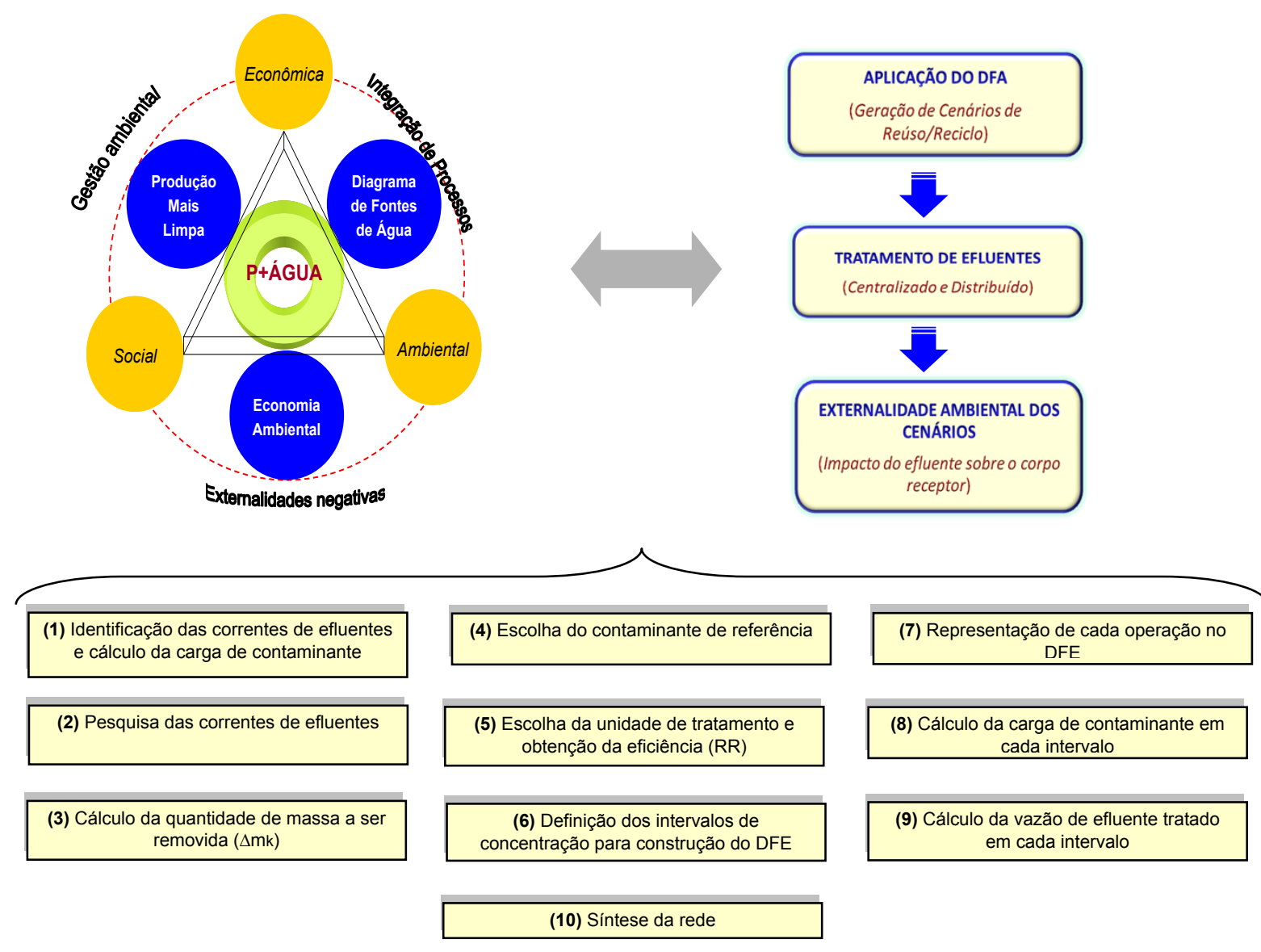

O procedimento para aplicação do DFE está descrito em detalhes no trabalho de Pacheco (2014). Trata-se de uma ferramenta complementar para análise e seleção de cenários promissores de reuso e tem como objetivo determinar a vazão mínima de efluente a ser tratado e que atenda à concentração máxima de descarte dos contaminantes.

A quantidade do contaminante $\mathrm{j}$ a ser removida na operação $\mathrm{k}\left(\Delta \mathrm{m}_{\mathrm{k}}\right)$, em $\mathrm{g} / \mathrm{h}$, é dada pela Equação 1.

$$
\Delta \mathrm{m}_{\mathrm{jk}}=\mathrm{f}_{\mathrm{k}} \mathrm{x}\left(\mathrm{C}_{\mathrm{jk}}-\mathrm{C}_{\mathrm{desc}, \mathrm{j}}\right)
$$

onde $\mathrm{f}_{\mathrm{k}}$ é a vazão da corrente de efluente, em t/h; $\mathrm{C}_{\mathrm{jk}}$ é a concentração do contaminante $\mathrm{j}$ na operação k, em ppm; e $C_{\text {desc,j }}$ é a concentração de descarte do contaminante j, em ppm.

Os intervalos de concentração do DFE são formados pelas concentrações originais de cada efluente, as concentrações de descarte do contaminante de referência e as concentrações de efluente tratado $\left(\mathrm{C}_{\mathrm{kt}}\right)$, estas obtidas pela eficiência de remoção (RR) do efluente no regenerador, de acordo com a Equação 2.

$$
\mathrm{Ce}_{\mathrm{kt}}=\mathrm{C}_{\mathrm{kj}} \mathrm{x}\left(1-\mathrm{RR}_{\mathrm{j}}\right)
$$


onde $\mathrm{C}_{\mathrm{kj}}$ é a concentração final do contaminante $\mathrm{j}$ na operação $\mathrm{k}$; e $\mathrm{RR}_{\mathrm{j}}$ é a eficiência do tratamento para a remoção do contaminante $\mathrm{j}$.

Cada operação é representada no DFE por uma seta com a origem na concentração de descarte e o fim na concentração original do contaminante de referência do efluente, por ordem crescente de concentração. A vazão de cada corrente é alinhada às operações no diagrama. O cálculo da vazão tratada prioriza a mistura com efluente mais sujo disponível, iniciando no intervalo de menor concentração. Duas regras devem ser satisfeitas: (i) realizar o cálculo da vazão de efluente a ser tratado através de tratamento externo somente quando não houver efluente "interno" com concentração menor que a do efluente a ser tratado disponível para mistura. Na disponibilidade de efluente interno, usar preferencialmente o proveniente da mesma corrente; (ii) para uma determinada corrente de efluente, a vazão a ser tratada em um determinado intervalo deve remover a quantidade de massa do respectivo intervalo.

A síntese da rede de tratamento distribuído de efluentes inicia-se a partir do último intervalo de cada operação no DFE.

\section{RESULTADOS E DISCUSSÃO}

A proposta de incorporação do DFE aos estágios do modelo P+ÁGUA levou à realização de um estudo de caso na qual o DFA já tenha sido previamente aplicado. Assim, foram utilizados os dados representativos de uma refinaria de petróleo com os cenários de reúso obtidos pelo DFA no estudo de Mirre et al. (2011). O DFE foi aplicado tanto para a configuração centralizada, que utiliza uma única forma de tratamento para todo o efluente, como a distribuída, que separa as correntes de acordo com a forma de tratamento que cada uma necessita. Tais tabelas foram utilizadas para ambas as possibilidades.

O problema considera três contaminantes nas correntes: Sais (A), Orgânicos (B) e $\mathrm{H}_{2} \mathrm{~S}$ (C). A água primária é dada como água potável (AF) e água tratada para fins específicos (AP). Os limites de descarte no corpo receptor considerados são: 240,6 ppm (A), 194,9 ppm (B) e $0,42 \mathrm{ppm}$ (C). A partir do cenário de reúso testado, optou-se por agregar correntes com características semelhantes, de modo a estabelecer um número menor de correntes na abordagem do DFE. As técnicas de regeneração são consideradas de forma geral, em termos de eficiência de remoção, apenas para ilustrar a aplicação do método, conforme Pacheco (2014) e Mirre et al. (2011).

A Figura 2 apresenta o resultado do diagrama de intervalos de concentração aplicado para o tratamento centralizado, e a respectiva rede encontra-se representada na Figura 3. Do mesmo modo, o método DFE foi aplicado considerando a possibilidade da configuração distribuída, com o diagrama da Figura 4 tendo sua rede representada pela Figura 5.

Figura 2 - Diagrama de intervalos de concentração. 


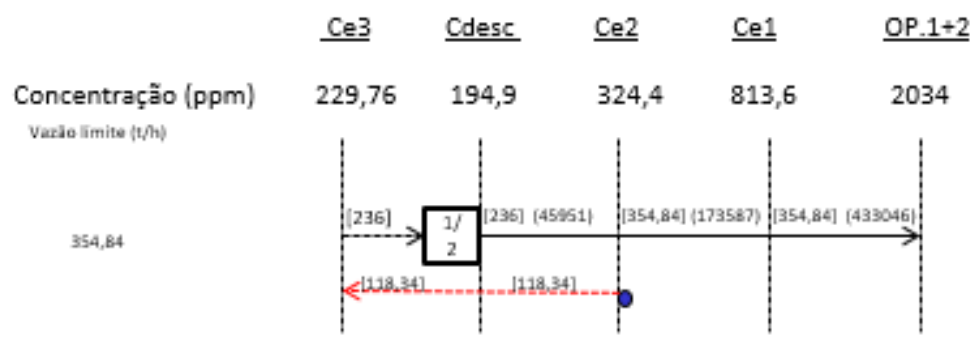

Figura 3 - Rede de tratamento centralizado.

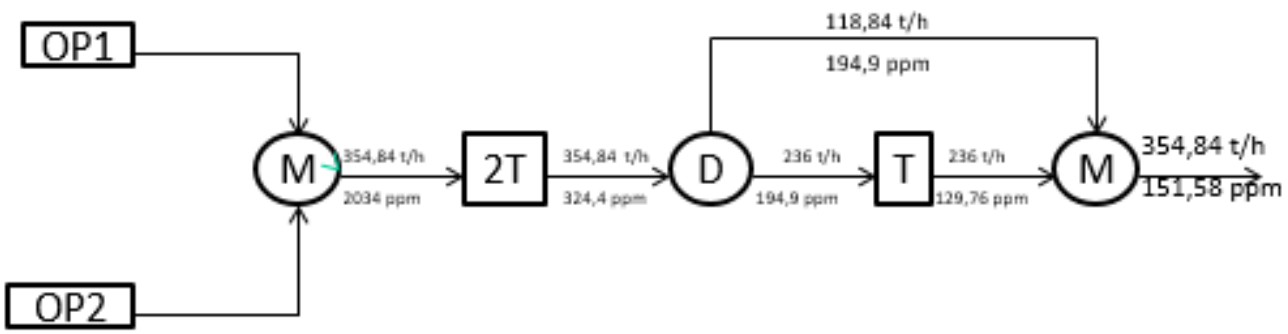

Figura 4 - Diagrama de intervalos de concentração.

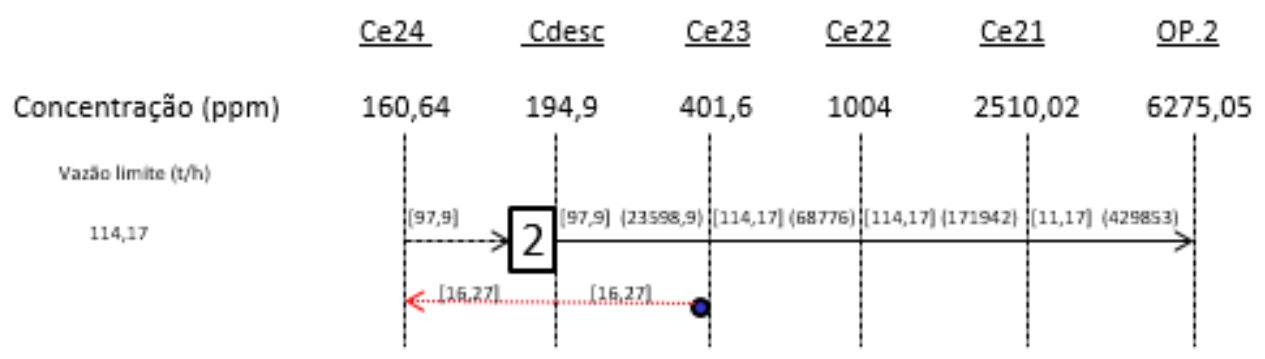

Figura 5 - Rede de tratamento distribuído

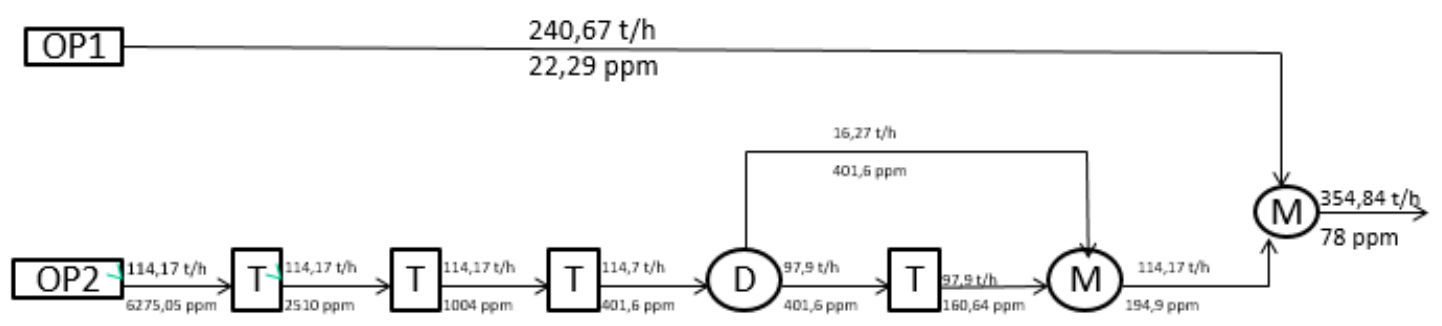

A partir dos valores de vazão a ser tratada em cada configuração, verifica-se que o tratamento centralizado gera $945,68 \mathrm{t} / \mathrm{h}$, enquanto que o distribuído necessita apenas de $440,41 \mathrm{t} / \mathrm{h}$ do efluente. Embora a finalidade aqui não seja definir as técnicas de tratamento, o 
custo para cada rede, dependente das respectivas vazões, foi gerado com base em informações relacionadas por Pacheco (2014). Para o centralizado, o custo foi de 2.532.471,90 \$/ano, enquanto que o distribuído ficou em 1.244.810,00 \$/ano, cerca de metade daquele apresentado pelo centralizado, sugerindo um incentivo para a implantação do tratamento distribuído.

\section{CONCLUSÃO}

Este trabalho teve como objetivo aplicar o procedimento algorítmico-heurístico DFE a um estudo de caso de refinaria de petróleo, voltado para reduzir a vazão de efluente a ser tratada por meio de sua configuração de tratamento. Adicionalmente, propôs-se a incorporação do DFE ao P+ÁGUA, para estender o gerenciamento de uso da água em processos. Foi possível constatar que o DFE direciona a configuração distribuída para a menor vazão de tratamento, com vantagem econômica e ambiental frente ao centralizado. Estudos amplos devem ser conduzidos de modo a avaliar outros sistemas multicomponentes, testar um conjunto maior de técnicas de tratamento, e inserir uma avaliação para o custo do impacto ambiental das redes.

\section{AGRADECIMENTOS}

Os autores agradecem ao $\mathrm{CNPq}$, pelas bolsas concedidas.

\section{REFERÊNCIAS}

DELGADO, B.E.P.C. Síntese de sistemas de regeneração e tratamento final de efluentes. Tese (D.Sc. em TPQB), UFRJ, Rio de Janeiro, 2008.

GOMES, J.F.S.; QUEIROZ, E.M.; PESSOA, F.L.P. Design procedure for water/wastewater minimization: single contaminant. Journal of Cleaner Production, v. 15, n. 5, p. 474-485, 2007.

HUNGARO, L.M. Desenvolvimento de algoritmo para síntese de tratamento distribuído para efluentes líquidos. Dissertação (M.Sc. em EQ), UFRJ, Rio de Janeiro, 2005.

MIRRE, R.C., Metodologia para o gerenciamento sustentável do reúso de águas e efluentes industriais por meio da Integração de Processos. Tese (D.Sc. em TPQB), UFRJ, Rio de Janeiro, 2012.

MIRRE, R.C.; YOKOYAMA, L.; PESSOA, F.L.P. Reúso de efluentes industriais em refinarias de petróleo usando o método DFA para sistemas regenerativos. Revista Ambiente \& Água, Taubaté, v. 6, n. 3, p. 127-151, 2011.

PACHECO, L.C. Minimização do consumo de água e de geração de efluentes líquidos na indústria de petróleo. Dissertação (M.Sc. em TPQB), EQ/UFRJ, Rio de Janeiro, 2014. 